\title{
Additive Manufacturing of Ti-6Al-4V with Added Boron: Microstructure and Hardness Modification
}

\author{
Ben Jackson ${ }^{1,2, a^{*}}$, Rob Torrens ${ }^{1, b}$, Leandro Bolzoni ${ }^{1, b}$, Fei Yang ${ }^{1, b}$, Mike Fry, ${ }^{2, b}$, \\ Aamir Mukhtar ${ }^{2, b}$
}

\author{
${ }^{1}$ Waikato Centre for Advanced Materials, School of Engineering, The University of Waikato, \\ Private Bag 3105, Hamilton 3240, New Zealand \\ ${ }^{2}$ TiDA Limited, 70 Windermere Drive, Poike, Tauranga 3112, New Zealand \\ aben.jackson@tida.co.nz, btorrens@waikato.ac.nz, cleandro@waikato.ac.nz, \\ dfyang@waikato.ac.nz, emike.fry@tida.co.nz, 'aamir.mukhtar@tida.co.nz
}

\begin{abstract}
Keywords: Titanium matrix composites, additive manufacturing, SLM, titanium boride, microstructure, hardness,
\end{abstract}

\begin{abstract}
Titanium alloy composites with titanium boride (TiB) discontinuous reinforcement have shown improved performance in terms of strength, stiffness, and hardness. Producing this composite through selective laser melting (SLM) can combine the advantages of freeform design with the ability to produce TiB reinforcement in-situ. In this study, SLM was used to consolidate a pre-alloyed Ti-6Al-4V (Ti64) and amorphous boron (B) powder mixture with the intent of producing $1.5 \mathrm{wt} \% \mathrm{TiB}$ reinforcement in a Ti64 matrix. The processing parameters of laser power and scanning speed were investigated for their effect on the density, microstructures, and hardness of the composite material. The results showed that the boron and Ti64 composite could achieve a density greater than $99.4 \%$. Furthermore, it was found that processing parameters changed the microstructural features of the material. The higher the energy density employed the more homogenous the distribution of boron modified material. Macro features were also observed with laser paths being clearly evident in the subsurface microstructure. Micro-hardness testing and density measurement also showed a corresponding increase with increasing energy density. Maximum hardness of $392.4 \mathrm{HV}$ was achieved in the composite compared to $354.2 \mathrm{HV}$ in SLM fabricated Ti64.
\end{abstract}

\section{Introduction.}

Additive Manufacturing (AM) has seen rapid development in recent years with a vast range of technologies and materials available for use in prototyping through to end use production. Developments in materials available for AM have expanded into metal matrix composite materials. Metal matrix composites, manufactured through traditional means, can be difficult to further process into final products. Thermal treatments can degrade reinforcements and machining/forming processes are made more difficult. Net or near-net shape fabrication of the composite is the best method to minimize post processes to achieve a functional product. AM has been evolving the fabrication industry by producing fully functional, net shape products with almost unrestricted design possibilities.

Titanium boasts the highest strength to weight ratio of any metal along with other notable properties of high corrosion resistance and biocompatibility. Titanium composites look to further exploit these properties and expand the applications of the material through making improvements in areas titanium performs less well. The ability to improve specific stiffness, high temperature strength, wear resistance and hardness have been focus areas of investigation [1,2]. A difficulty encountered in developing titanium composites is its reactivity with many common reinforcing materials. Oxides and carbides are degraded by titanium's reactivity with oxygen and carbon. Reinforcements including: $\mathrm{TiC}, \mathrm{TiB}, \mathrm{SiC}$, and $\mathrm{WC}[1,3-5]$ have been used to develop different composites of titanium. 
$\mathrm{TiB}$ is recognized as being one of the most beneficial reinforcement materials for titanium [6]. $\mathrm{TiB}$ is stable chemically in a titanium matrix, preventing degradation of the interface strength. Similar thermal expansions coefficients of $\mathrm{Ti}$ and $\mathrm{TiB}$ (room temperature $8.6 \times 10^{-6}{ }^{\circ} \mathrm{C}^{-1}$ and $7.45 \times 10^{-6}{ }^{\circ} \mathrm{C}^{-1}$ respectively [7]) further improve the compatibility of a composite of these materials. $\mathrm{TiB}$ can be synthesized via in-situ reaction within titanium alloys via $\mathrm{TiB}_{2}$ or elemental boron addition. Cai et al. [8] has shown that TiB will preferentially form in excess titanium as it is the most thermodynamically stable product of reaction.

TiB forming in situ with titanium alloys allows the possibility of AM for this metal matrix composite. SLM is a process of AM that has seen application in fabrication of Ti matrix composites. A laser is used to selectively melt metal powders layer by layer into net shape components. The laser provides the energy to generate a reaction between boron compounds in the powder and the titanium to generate the $\mathrm{TiB}$ reinforcement in situ. $\mathrm{TiB}_{2}$ and elemental boron powders have both been used as additives to titanium and titanium alloys for reactive processing.

Low levels of boron have shown improvement to titanium's properties of strength and stiffness. $5 \mathrm{wt} \%$ of $\mathrm{TiB}_{2}$ powder has been reported to achieve optimum fracture toughness and bending strength in a titanium composite [9]. Greater than $5 \mathrm{wt} \%$ of $\mathrm{TiB}_{2}$ proved to be detrimental to the performance of the material in these respects. A previous study [10] looked at powder extrusion of a Ti64 -TiB composite. Boron powder additions of $0.5 \mathrm{wt} \%, 1.0 \mathrm{wt} \%$ and $1.5 \mathrm{wt} \%$ were made to Ti64 powders with the generation of $2.6 \mathrm{wt} \%, 5 \mathrm{wt} \%$ and $7.4 \mathrm{wt} \% \mathrm{TiB}$ respectively. $0.5 \mathrm{wt} \%$ of boron addition to pre-alloyed Ti64 generated an increase in tensile strength while maintaining some ductility. Greater additions of boron caused the material to fail in the elastic region however the powder mixture consisted of $\mathrm{Ti}$ and $60 \mathrm{Al}-40 \mathrm{~V}$ master alloy so the brittle nature may not be attributed to just the boron.

This work looks at applying TiB reinforcement to the most commercially utilized titanium alloy Ti64. The AM process of SLM will be used to generate the composite from a simple mixture of Ti64 alloy powder and elemental boron powder. Investigation into microstructural development and ability of this method to produce a homogeneous material will be undertaken with emphasis on producing a fully dense product. Hardness will be used as a measure of the materials mechanical performance improvement.

\section{Experimental.}

Grade 23 Ti64 ELI Titanium alloy powder was used as the starting material. Table 1 describes the actual powder composition compared to ASTM standard F136. Powder size was approximately normally distributed with $\mathrm{D}_{90}$ of $50 \mu \mathrm{m}$ and $\mathrm{D}_{10}$ of $16 \mu \mathrm{m}$. Pure amorphous boron powder was used as the additive for reactive processing into the composite material. Particle size is approximately $1 \mu \mathrm{m}$ from SEM observation.

The powders were simply mixed by addition of the boron to the Ti64 powder and then tumbled for 2 hours. This approach generated an even distribution of boron over the surface of Ti64 particles as seen in Figure 1. The small size of the boron powder relative to the Ti64 could lead to an accumulation in crevasse between connected particles. This may result in some localized areas of the consolidated material being rich in boron. Also, as the boron is coated on the surface of the Ti64 powder, smaller particles will have a greater amount of boron in contact compared to their volume. This could create a difference in the consolidated material. Assuming the size distribution of Ti64 powder in the powder bed is even and that multiple particles are contributing to the melt pool at any point in time this difference in boron is likely to be small.

Table 1. Ti64 ELI powder composition compared to ASTM specification.

\begin{tabular}{|c|cccccccc|}
\cline { 2 - 8 } \multicolumn{1}{c|}{} & $\mathrm{Al}$ & $\mathrm{V}$ & $\mathrm{O}$ & $\mathrm{C}$ & $\mathrm{Fe}$ & $\mathrm{N}$ & $\mathrm{H}$ & $\mathrm{Ti}$ \\
\hline Actual & 6.02 & 3.96 & 0.0837 & 0.012 & 0.05 & 0.0062 & 0.0022 & Bal. \\
Received [wt\%] & & & & & & & & \\
Standard ASTM & $5.5-$ & $3.5-$ & $<0.13$ & $<0.08$ & $<0.25$ & $<0.05$ & $<0.012$ & Bal. \\
F136 [wt\%] & 6.5 & 4.5 & & & & & & \\
\hline
\end{tabular}


An initial trial using $0.5 \mathrm{wt} \%$ boron was performed. Under a range of build parameters, the produced samples proved to be extremely brittle and cracked during the building process. The boron content was halved to $0.25 \mathrm{wt} \%$ or $1.5 \mathrm{wt} \% \mathrm{TiB}$. Under the same conditions as the previous trial the parts were successfully fabricated. This paper investigates the blend of $0.25 \mathrm{wt} \%$ boron with Ti64 as an initial study into the influence small amounts of boron have on AM of Ti64.

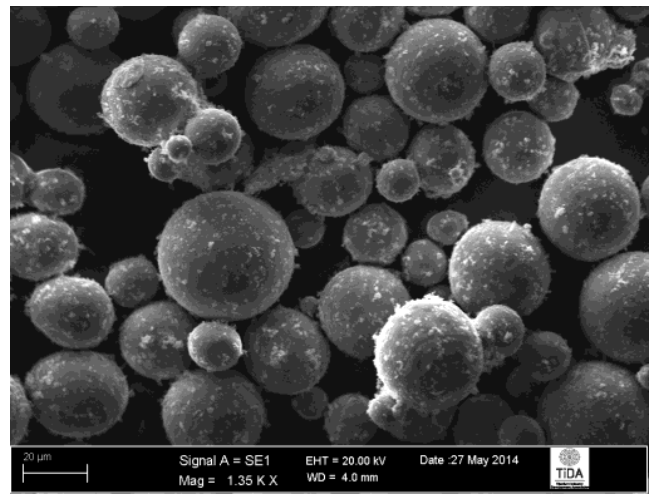

Figure 1. Distribution of boron powder over the surface of Ti64 powder after tumbling for 2 hours.

Production of samples was performed on an EOSM270 SLM machine with a variable Ytterbium fiber laser (max. $200 \mathrm{~W}$ ), wavelength 1060-1100 nm. Samples were fabricated at a layer thickness of $30 \mu \mathrm{m}$ and hatch spacing $100 \mu \mathrm{m}$. The variables of the process investigated were laser power and scanning speed. Parts were fabricated with zig zag hatching across the full cross-section of parts. Rotation of hatching vectors between layers of 67 degrees was maintained to prevent alignment of the pattern on consecutive layers.

In AM, the fabrication parameters are often combined into a representative formula to give comparison between different build strategies. This is most commonly volumetric energy density $\left(E_{v}\right)$ for the SLM process which combines; laser power $(P)$, scanning speed $(v)$, hatch spacing $(\delta)$, and layer thickness (h) (Eq. 1) [5, 11, 12].

$$
\mathrm{E}_{v}=\frac{\mathrm{P}}{\mathrm{v} \times \delta \times \mathrm{h}}\left[\mathrm{J} / \mathrm{mm}^{3}\right] \text {. }
$$

Density samples were produced following a full factorial experimental design for laser powers between 150-190W and scanning speeds of 900-1650 mm/s. These samples consisted of cylinders $8 \mathrm{~mm}$ in diameter, $10 \mathrm{~mm}$ high, produced in triplicate for each condition. Measurement was performed using Archimedes method. A calibrated balance accurate to $0.0005 \mathrm{~g}$ was used. Triplicate samples were measured individually and then combined to provide 4 data points for each condition and minimize error associated with measuring small samples. Relative density values were calculated using $4.430 \mathrm{~g} / \mathrm{cm}^{3}$ for Ti64 and $4.432 \mathrm{~g} / \mathrm{cm}^{3} \mathrm{Ti} 64+1.5 \mathrm{TiB}$ as theoretical density of the material.

For microstructural analysis and hardness testing, the build parameter variables investigated are displayed in Table 2. These samples consisted of 16 segment disks as displayed in Figure 2 which simplified sample preparation for analysis. Each segment is fabricated with different laser parameters during a single build process. The segments were connected via the base only to prevent thermal influence of neighboring parameters. The assignment of parameters to segment was randomized to further reduce systematic error. A full factorial design was used to investigate laser power and scanning speed between $130-190 \mathrm{~W}$ and $900-1500 \mathrm{~mm} / \mathrm{s}$ respectively. This was combined with a sweep of laser power between 70-130 W for constant speed of $600 \mathrm{~mm} / \mathrm{s}$. This range of parameters was selected to avoid over-melting at energy density greater than $75 \mathrm{~J} / \mathrm{mm}^{3}$. In a previous experiment this over-melting caused disruption to neighboring segments during the building process. 
Table 2. Build parameter conditions investigated for microstructure and hardness showing resultant energy density for each condition $\left[\mathrm{J} / \mathrm{mm}^{3}\right]$.

\begin{tabular}{|c|c|c|c|c|c|c|c|c|}
\hline & \multicolumn{8}{|c|}{ Laser power [W] } \\
\hline \multirow{5}{*}{ 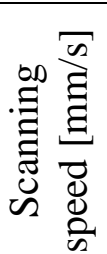 } & & 70 & 90 & 110 & 130 & 150 & 170 & 190 \\
\hline & 600 & 38.9 & 50.0 & 61.1 & 72.2 & & & \\
\hline & 900 & & & & 48.1 & 55.6 & 63.0 & 70.4 \\
\hline & 1200 & & & & 36.1 & 47.2 & 47.2 & 52.8 \\
\hline & 1500 & & & & 28.9 & 33.3 & 37.8 & 42.2 \\
\hline
\end{tabular}

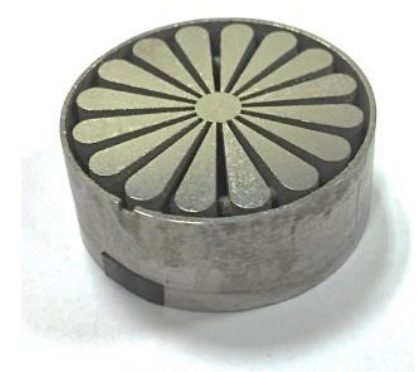

Figure 2. Ti64 segmented disk sample produced by SLM for microstructure and hardness testing.

The segmented disks were rough ground $2 \mathrm{~mm}$ down from the top surface to expose a plane representative of the bulk material. This cross section was prepared using standard metallographic polishing techniques followed by etching with Kroll's reagent to expose the microstructure. Optical micrographs were taken of the material in each condition for comparison of macro phase and distribution features. Scanning electron microscopy (SEM) backscatter electron (BSE) images were used to further examine the microstructure. Hardness testing was performed on a Buehler Micromet 5100 Series microhardness tester following standard procedures for HV0.5 measurement. $500 \mathrm{~g}$ hardness indentations were performed for a hold duration of $10 \mathrm{~s}$. A minimum of 5 measurements were taken per sample to reduce error.

\section{Results and Discussion.}

Microstructures. Micrographs of samples fabricated with different energy density display a significant difference in microstructure between Ti64 and the boron-added material. The Ti64 as built material (Figure 3: A, C, and E) has relatively similar microstructures across the range of build energies applied. The grains are fairly uniform at just under $100 \mu \mathrm{m}$ in size.

Boron modified TI64 microstructure fabricated using the same build parameters has resulted in a very different morphology (Figure 3: B, D, and F). The boron added material appears to retain features corresponding to the scanning of the laser. Figure 3-F shows this most clearly, there are three different orientations of these scan paths which correspond to the rotation of the laser hatching by 67 degrees every layer. The appearance of three rotated hatches in a single cross-section of the sample is evidence that laser exposure of a layer will influence the materials structure several layers below the newly consolidated one. In this case a depth of at least three layers or $90 \mu \mathrm{m}$.

At low energy input $\left(28.9 \mathrm{~J} / \mathrm{mm}^{3}\right.$ in Figure 3: A and B) the Ti64 shows irregular porosity which is consistent with incomplete melting and consolidation of the sample [12]. This is supported in the boron added material as there is clear evidence of un-melted powder particles (the white round particles) retained in the material. This indicates there is insufficient energy to generate full melting and more complete mixing between the boron and Ti64.

Increasing energy density $\left(52.8 \mathrm{~J} / \mathrm{mm}^{3}\right.$ in Figure 3: C and D) greatly increases the uniformity of the material. There is effectively no porosity evident in the Ti64 sample and the boron added material has become more uniform. There are still occasional areas where Ti64 has not mixed with the boron however there is no evidence of un-melted particles. 
At higher energy $\left(72.2 \mathrm{~J} / \mathrm{mm}^{3}\right.$ in Figure 3: E and F) porosity becomes evident in the Ti64 sample once more. This is consistent with keyhole and gas entrapment porosity which is the generation of pores due to high energy input creating deep melt pools that trap gas bubbles within them [12, 13]. The boron added material did not display the same porosity features. Again, the material appears very evenly mixed with very few areas where unmodified Ti64 is present.

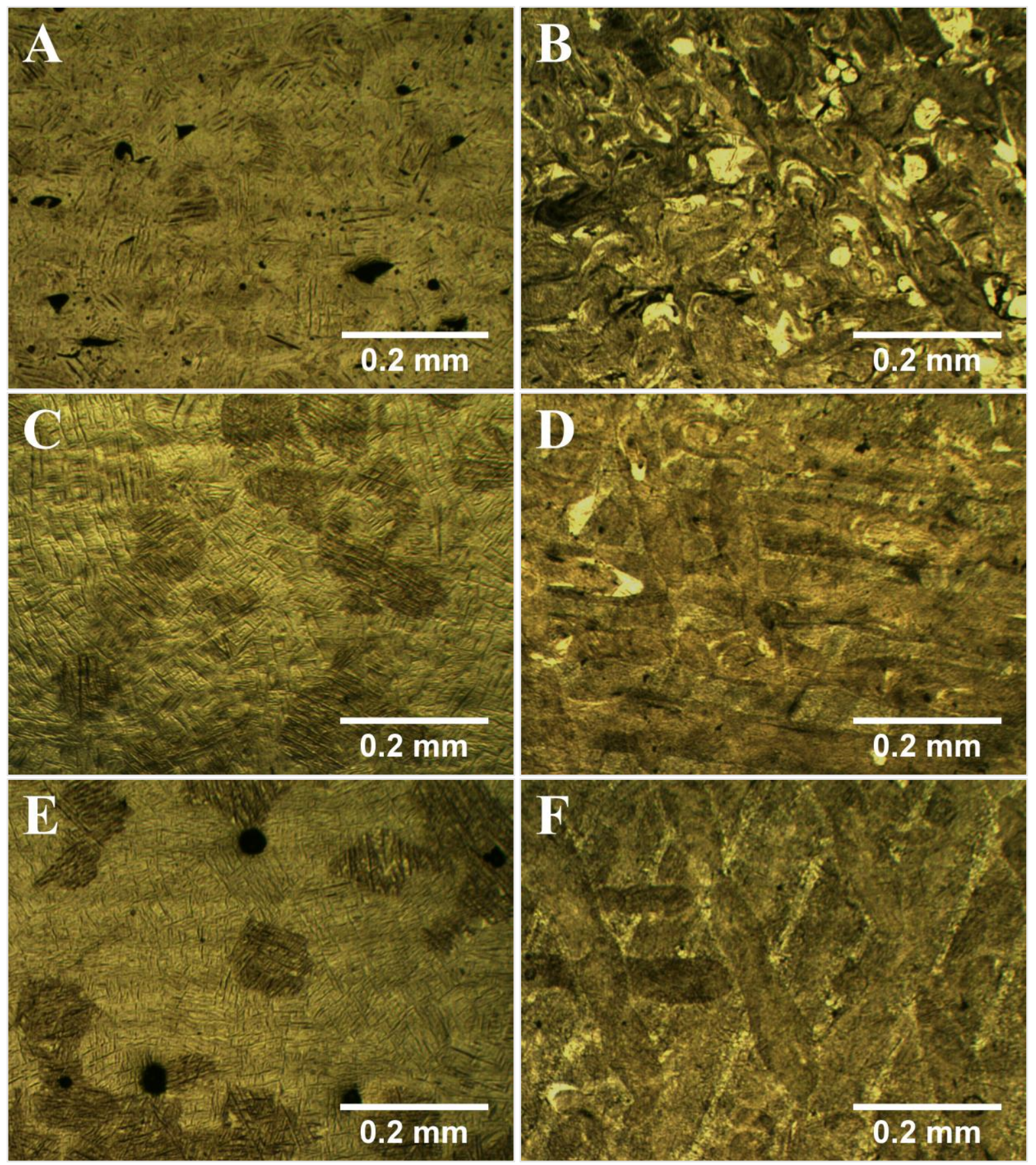

Figure 3. Optical micrographs of SLM fabricated Ti64 (left images) and boron modified Ti64 (right images). Energy density for consolidation increases from top to bottom $\left(28.9,52.8,72.1 \mathrm{~J} / \mathrm{mm}^{3}\right)$.

BSE images in Figure 4 show the extent that the microstructure has been modified by the addition of boron. There is significant grain refinement in the boron added material. Empirically, grains have reduced from approximately $100 \mu \mathrm{m}$ average size in Ti64 to between 10 and $20 \mu \mathrm{m}$. This is consistent with observations in other work where boron was identified as contributing to the grain refinement of titanium alloys [14].

The structure has the appearance of $\alpha^{\prime}$ martensite attributed to high cooling rates experienced during SLM and is consistent with that of literature [15]. The boron modified material also displays 
martensitic $\alpha^{\prime}$ structure however, no clear visual evidence of TiB particles is apparent. TiB is expected to result from the reaction of boron in excess titanium. This forms as small, high aspect whiskers. It is possible that $\mathrm{TiB}$ whiskers are present however the martensite pattern would obscure it from visual identification due to the similar appearance. Further investigation into identifying the boron phase generated is needed to complete the analysis of these microstructures.
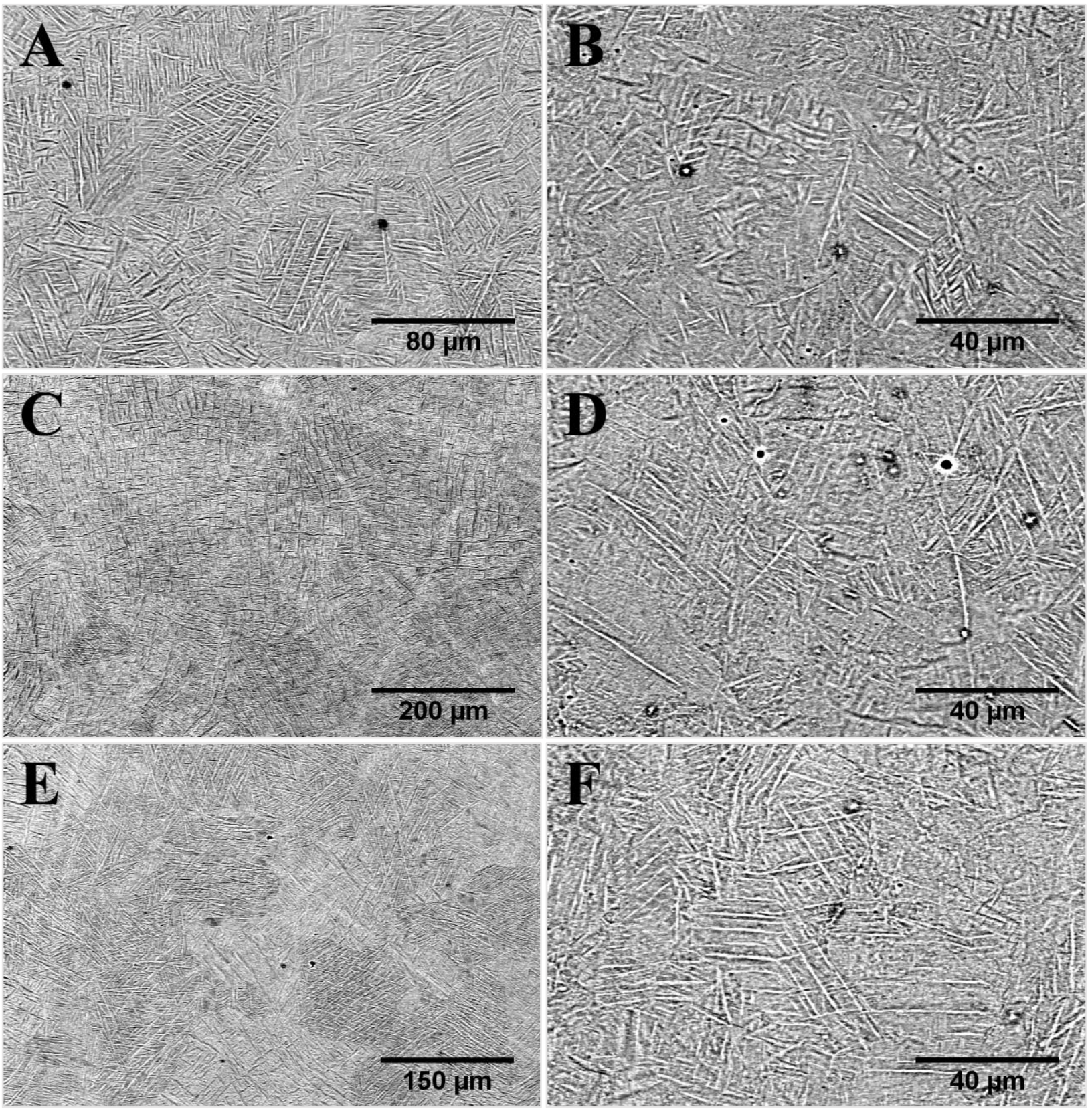

Figure 4. SEM BSD images of SLM fabricated Ti64 (left images) and boron modified Ti64 (right images). Energy density for consolidation increases from top to bottom $(28.9,52.8,72.1 \mathrm{~J} / \mathrm{mm} 3)$.

Hardness and Density. The relationship between relative density of SLM produced samples and the fabrication energy density is displayed in Figure 5. Density for the two materials again follows an increasing trend. No significant difference in density is apparent with the addition of boron to Ti64. The density data appears to display two distinct relationships. Below $45 \mathrm{~J} / \mathrm{mm}^{3}$ density sharply declines with decreasing energy input. Above this value density remains relatively constant with energy input variation having scatter between 99 and $99.5 \%$ dense. This is consistent with other observations of build parameters influence on density [12]. Below $45 \mathrm{~J} / \mathrm{mm}^{3}$ there is insufficient energy to fully melt the material and thus porosity is introduced. This is clearly visible in microstructures Figure 3: A and B. The result of high energy density is also expected to decrease 
the relative density of SLM parts through keyhole porosity and inert gas entrapment however this is not clearly evident in the data. From microstructure images (Figure 3: E and F) it can be seen that there is an increase in porosity so it can be estimated that density would decrease if the study were to investigate higher energy parameters.

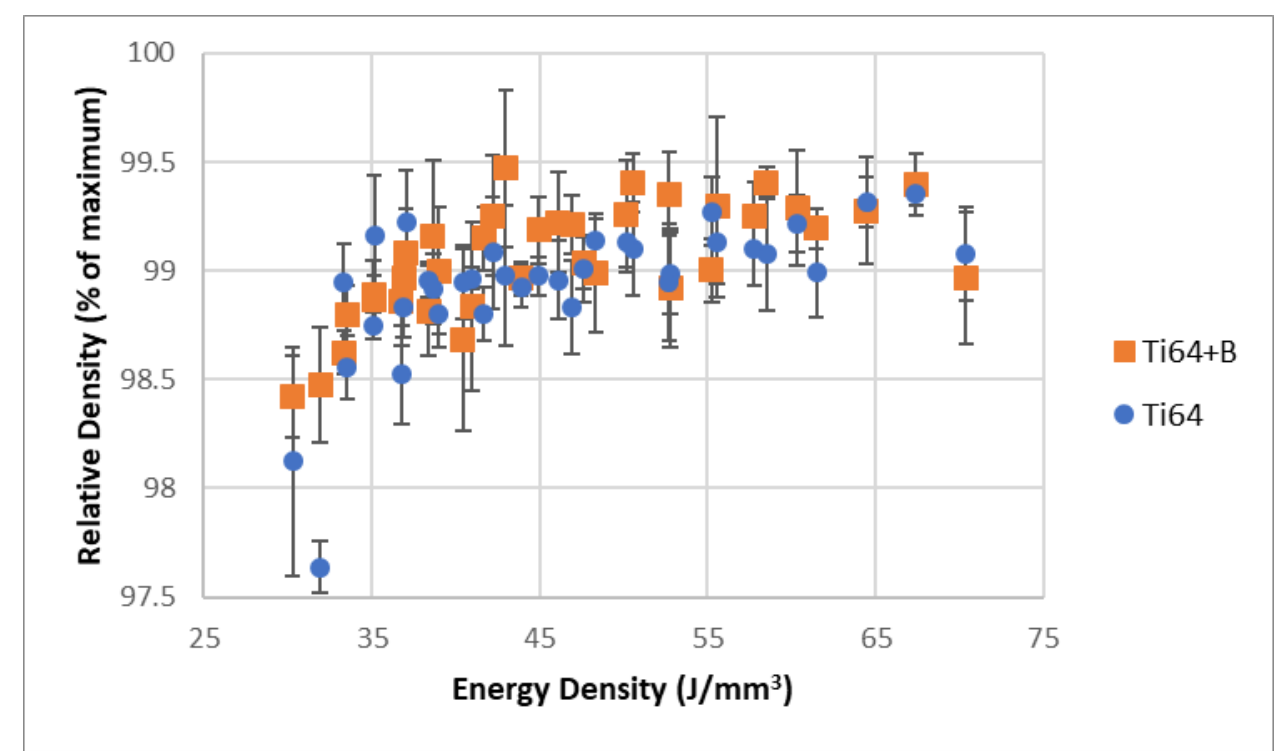

Figure 5. Density of SLM fabricated samples against volumetric energy density. Density is plotted as a $\%$ of theoretical maximum for each material. Error bars \pm 2 std. dev.

Figure 6 shows the resulting hardness with respect to energy density for Ti64 and boron added material. There is an increase in hardness for the boron added material across the entire range of conditions of the order of $30 \mathrm{HV}$. The boron added material appears to reach a maximum hardness of approximately $390 \mathrm{HV}$ at energy input greater than $45 \mathrm{~J} / \mathrm{mm}^{3}$. Ti64 does not obviously demonstrate this plateau of hardness. Further study would be needed into higher energy density parameters to identify if Ti64 reaches a hardness limit.

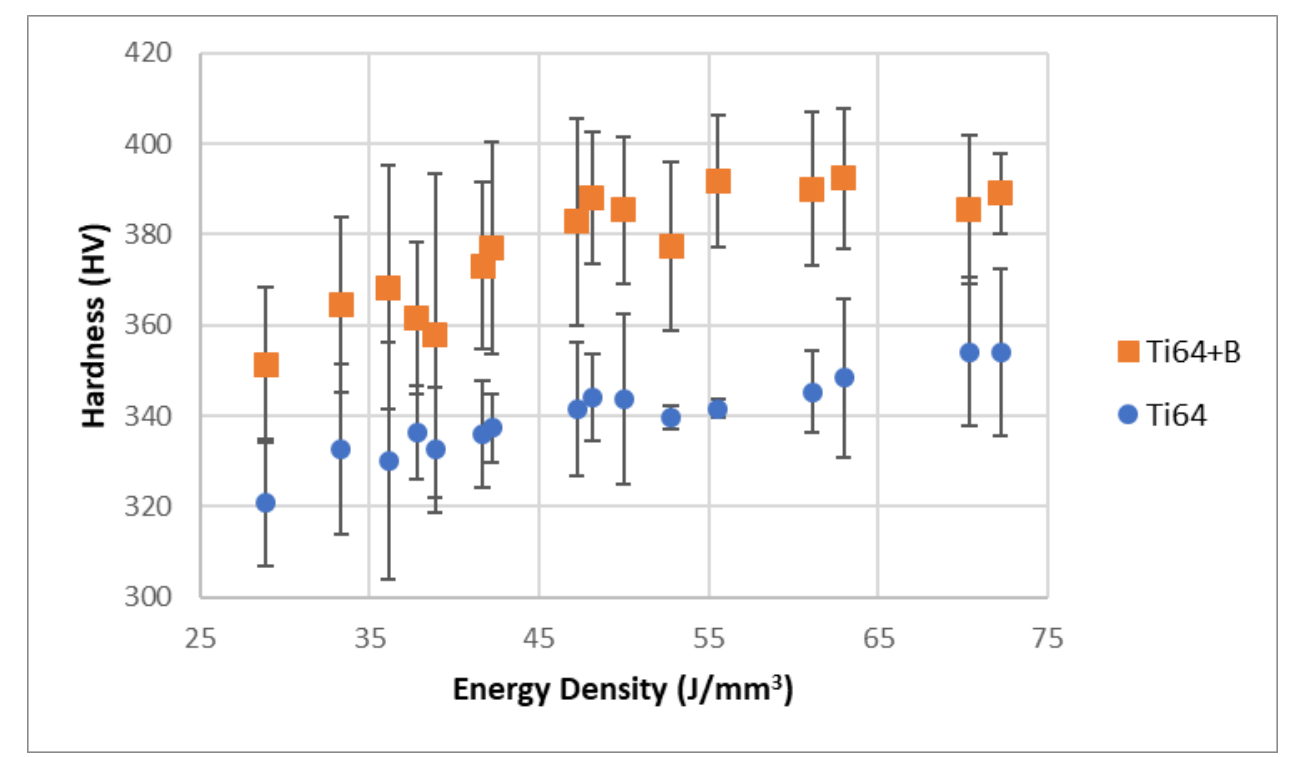

Figure 6. Vickers hardness versus linear energy input for SLM fabricated samples of Ti64 and TI64+B. Error bars \pm 2 std. dev. 


\section{Conclusions}

- The addition of $0.25 \mathrm{wt} \%$ boron to Ti64 for fabrication via SLM increases the hardness of the as built material by approximately $30 \mathrm{HV}$ compared to Ti64 alloy across the range of fabrication parameters investigated. The maximum hardness of the Ti64/boron material was 392.4HV.

- There is no significant difference in density between the Ti64 and boron added materials. Maximum relative density of just below $99.5 \%$ was achieved for both materials.

- The microstructure of the two materials differs greatly. Ti64 displays a relatively even microstructure across the range of build parameters. Porosity is generated at low and high energy parameters consistent with under-melting and gas entrapment porosity respectively. The boron has a significant influence on grain refinement in the as built material.

\section{References}

[1] S. Pouzet, P. Peyre, C. Gorny, O. Castelnau, T. Baudin, F. Brisset, C. Colin, P. Gadaud, Additive layer manufacturing of titanium matrix composites using the direct metal deposition laser process, Materials Science and Engineering: A 677 (2016) 171-181.

[2] C. Cai, B. Song, C. Qiu, L. Li, P. Xue, Q. Wei, J. Zhou, H. Nan, H. Chen, Y. Shi, Hot isostatic pressing of in-situ TiB/Ti-6Al-4V composites with novel reinforcement architecture, enhanced hardness and elevated tribological properties, Journal of Alloys and Compounds 710 (2017) 364374.

[3] C. Poletti, M. Balog, T. Schubert, V. Liedtke, C. Edtmaier, Production of titanium matrix composites reinforced with SiC particles, Composites Science and Technology 68(9) (2008) 21712177.

[4] J.A. Vreeling, V. Ocelík, J.T.M. De Hosson, Ti-6Al-4V strengthened by laser melt injection of WCp particles, Acta Materialia 50(19) (2002) 4913-4924.

[5] H. Attar, M. Bönisch, M. Calin, L.-C. Zhang, S. Scudino, J. Eckert, Selective laser melting of in situ titanium-titanium boride composites: Processing, microstructure and mechanical properties, Acta Materialia 76 (2014) 13-22.

[6] T. Saito, T. Furuta, T. Yamaguchi, Development of low cost titanium alloy matrix composites, in: F.H. Froes, J. Storer (Eds.) Recent Advances in Titanium Metal Matrix Composites, Rosemont, Illinois, 1994.

[7] K.S. Ravi Chandran, K.B. Panda, S.S. Sahay, TiBw-reinforced Ti composites: Processing, properties, application prospects, and research needs, JOM 56(5) (2004) 42-48.

[8] L. Cai, Y. Zhang, L. Shi, H. Yang, M. Xi, Research on development of in situ titanium matrix composites and in situ reaction thermodynamics of the reaction systems, Journal of University of Science and Technology Beijing, Mineral, Metallurgy, Material 13(6) (2006) 551-557.

[9] S. Wei, Z.-H. Zhang, F.-C. Wang, X.-B. Shen, H.-N. Cai, S.-K. Lee, L. Wang, Effect of Ti content and sintering temperature on the microstructures and mechanical properties of $\mathrm{TiB}$ reinforced titanium composites synthesized by SPS process, Materials Science and Engineering: A 560 (2013) 249-255.

[10] H. Lu, D. Zhang, B. Gabbitas, F. Yang, S. Matthews, Synthesis of a TiBw/Ti6Al4V composite by powder compact extrusion using a blended powder mixture, Journal of Alloys and Compounds 606 (2014) 262-268.

[11] A. Simchi, H. Pohl, Effects of laser sinterinng processing parameters on the microstructure and densification of iron powder, Materials Science and Engineering: A 359(1-2) (2003) 119-128. 
[12] G. Kasperovich, J. Haubrich, J. Gussone, G. Requena, Correlation between porosity and processing parameters in TiAl6V4 produced by selective laser melting, Materials \& Design 105 (2016) 160-170.

[13] W.E. King, H.D. Barth, V.M. Castillo, G.F. Gallegos, J.W. Gibbs, D.E. Hahn, C. Kamath, A.M. Rubenchik, Observation of keyhole-mode laser melting in laser powder-bed fusion additive manufacturing, Journal of Materials Processing Technology 214(12) (2014) 2915-2925.

[14] F. Tang, S. Nakazawa, M. Hagiwara, Effect of boron microalloying on microstructure, tensile properties and creep behavior of Ti-22Al-20Nb-2W alloy, Materials Science and Engineering: A 315(1-2) (2001) 147-152.

[15] L. Thijs, F. Verhaeghe, T. Craeghs, J.V. Humbeeck, J.-P. Kruth, A study of the microstructural evolution during selective laser melting of Ti-6Al-4V, Acta Materialia 58(9) (2010) 3303-3312. 